\title{
Impact of Digital Divide and Public Libraries
}

\author{
Dr. Devendra Kumar Gautam \\ Librarian M.P. Government Degree College, Sikandra Rao (Hathras), India
}

\begin{abstract}
The Term "digital divide" refers to the perceived gap between those that have access to computer, internet and online information. The digital dives commonly used in relation to age, gender, income group and language among people within a community or country. Digital Divide" has been applied to the gap that exists in most Countries between those with ready access to the tools of information and communication technology and the knowledge that they provide access to and those without such access skills. It is used to focus on how information and communication technology (ICT) attests individuals, communities and countries. A further gap between the developed and under developed world in the uptake of technology is evident with in the global community and may be of even greater significant. Public libraries in determining and managing their public access computing services to bridging the digital divide in its community. Public libraries are more significant in bridging the gap of digital divide. The relevance of these strategies to developing countries and strategies for reducing the international digital divide are also explored. Libraries have long been essential agents in fostering peace and human values. Libraries are now operating digitally, and their digital services open up a new channel to the universe of knowledge and information connecting cultures across geographical and social boundaries. The phenomenon of digital discrimination prevailing among various social, political and working groups has led to the emergence of digital information rich and digital information poor groups within societies and perhaps in the global environment.
\end{abstract}

\section{Introduction}

A "digital divide" persists between those who have the training and access to technologies that enable them to take advantage of the Internet and advanced communications technologies and those who are unable to take full advantage of the tools, skills, benefits, and employment opportunities available in the new economy. The types of digital divide are

\begin{tabular}{|l|l|l|l|}
\hline Stage & Types & Terminology & Description \\
\hline Early adoption & Access divide & Early digital divide & $\begin{array}{l}\text { Description on difference between persons } \\
\text { can access and can not }\end{array}$ \\
\hline Take-off & Usage divide & Primary digital divide & $\begin{array}{l}\text { Description on difference between users and } \\
\text { not users }\end{array}$ \\
\hline Saturation & $\begin{array}{l}\text { Divide stemming from the } \\
\text { Quality of Use }\end{array}$ & Secondary digital divide & Description on difference within users \\
\hline
\end{tabular}

Usually it fills the gap between the countries those are greater and lesser access of information communication technology (ICT) the main objective and strategies in this regard are social inclusion and individual \& community empowerment. Computer, networks, software, internet etc. are enabling technology in digital inducing. The information revolution is exciting, and at its best, is about expanding equality of opportunity for all in our society.

Digital divide refers to a substantial symmetry between two or more population in the distribution and effective use of information and communication resources. The world we live in has been changing rapidly with the emergence of the ubiquitous Society bringing forward extraordinary benefits and opportunities together with new challenges. The ability to create and utilize information plays a significant role in both socio-economic structures of our lives. On the other hand ICT has faced serious problem of digital divide between developed and developing countries. The digital divide affects many nations of the developing world. The term encompasses inadequate funding, a lack of necessary computer and internet skills and a lack of English language proficiency that hinder expansion and use of digital information resources. (Dubey. P, 2010).Factors influencing digital divide vary from region to region the digital divide is depending and the differences in the usage of communication resources between countries and regions intensifying. The digital divide can be defined as the gap between individuals, households, business and geographical areas at different socio- economic levels with regards both to their opportunities to access ICTs and to their use of the internet for a wide variety of activities. As internet has rapidly growth to underline almost aspect of the global economy, the term "Digital divide" has often been referred to internet access it is a divide that affects and reinforces fundamental economic and social divides between and within countries and is threatening to further exacerbate these inequalities.(Singh.K, 2012) 


\section{Digital Divide And Public Libraries}

The digital divide can be broken into three levels: (a) Global divides, (b) Social divide and (c) democratic divide. Most of the focus around the digital divide has centered on access to computers and the Internet. Absent from these debates has been what information and activities are available over the Internet- the "there" online. Recent reports on the state of the digital divide, though optimistic, still indicate that the explosive growth in new technologies have not occurred evenly across boundaries of geography, race, socio-economic status, educational level, disability, gender, age, Technology skills are already critical for stable, high-paying jobs. As the information economy continues to develop, the opportunity to develop skill in advanced technologies will become a more central part of what is needed to ensure all segments of society participate fully in the Digital Age. Making the transition to the Digital Age and an information technology economy requires new policies to ensure that presently underserved individuals possess the skills needed in the information sector. Main questions are in this approach are:-

1. How technologies do affect human rights, civic participation and social inclusion?

2. How technologies do affect development?

3. What is in social \& political barriers for access the technology?

The implementation of ICTs is occurring; in a context where the cultural and institutional barriers are not well addressed. The assumption often made is that if one just purchases a few computers and modems, a post-industrial society can magically result. ICTs were generally seen as the basic tool for survival in the next century. ICTs were seen to enhance efficiency in the workplace. There was a high belief in ICT ability to increase the ease and speed of social communication and at the same time obviates the problem of transportation. It helps to solve socio-economic problems. The most appropriate technologies were seen as the ones that enabled the communities and organizations to communicate more efficiently. ICTs promote distance education at all levels; instantaneous availability of data through ICTs; the future of education is heavily dependent on ICTs; Internet access helps productivity, innovation and entrepreneurship to flourish; ICTs are useful for job search by youths; and ICTs are essential for the knowledge era. A range of factors were seen as inhibiting the use of new ICTs are high cost of the ICTs leading to restriction of access to the new technologies; lack of deregulation and government legislation which gives monopoly to a few information technology companies; poverty and harsh economic climate; infrastructural problems such as inadequate telephone lines and lines cutting off when someone is logged onto the Internet; health and social welfare commitments undercutting attention to ICTs; lack of basic education and computing skills; and political culture which discourages open sharing of information. In all the countries and regions we found that ICT growth and development are being driven by the private sector with the support from the government.

Public library is a nonprofit library maintained for public A public library, or any library (schools, institutions, social organizations, individual communities, etc.) is created with the intention of providing free public access to reading material, with the altruistic goal of educational enlightenment and the better welfare of the people. Many libraries are in operation with a specialization of a specific subject or focus (law libraries, science libraries, etc.). Public library as a rescuer for have not's who experience the impact of digital divide on their welfare. The rules and efforts of public libraries to close the digital gap are still largely unknown.

Result from this study can assist public libraries in determining and managing their public access computing services to bridging the digital divide in its community. Development of public libraries patrons can be done via

1. The use of computer, Internet in the public library.

2. The viewpoint about the access to computers and the internet in their lives.

3. Suggestions for improvement for public computing is

4. The library patron's should be participated in the activities on the interne

\section{Overview Of The Digital Divide}

The advent of information and communication technologies has indeed led to technological revolution across the globes and it continues to change the global social and economic milieus of countries making use of these technologies. Now developed countries have become knowledge societies because of this technological revolution and most developing countries are also putting strategies in place to bridge the digital divide by encouraging the use of ISTs. (Stevention, 1988). (Osunkunle, 2008). It must be pointed out that digital divide exits in these developing and mostly especially under- developed countries as most people still do not have access to ICTS.

According to lesame (2005:3) the term digital divide refers to the gap between the access of individuals, households, organizations, countries and regions at different socio-economic levels of ICTS and internet usage, globally, digital divide exacts and this is evident in the fact that developed nations like U.S.A and Switzerland have significant access to ICTS while develop nations in Africa like mail, Ethiopia and Congo do not enjoy considerable access. However, the rate of access to pcs in some African countries like Nigeria, congo 
is less than 1 out of every 100 people (bridging the digital divide in Africa, 2003, world Telecommunications ICTS indicates, 2004).

\section{Digital Divide, National and Global distinctions}

The digital divide had different characteristics both nationally and globally. Nationally the digital divide in different because each country has a unique history, language, and population characteristics. The total population of the world is nearly 7 billion but the estimate of internet users is only 1 billion or $15 \%$, (according to worldwide CIA world fact book, 2007). The US alone accounts for $20 \%$ of the users worldwide. Globally the factors that affect the digital divide are similar to US, with some exceptions. However, in a global context, race could be a factor, because if we compare all the people in developed countries that have access to ICT to all the people in develop country who do not have race is co- related. (A.T.lucky, 2013).

\section{Digital Divide and Information Literacy}

Various developing countries could not utilize the full potentialities of their people because of literacy. Libraries must gear up to play an important role in imparting information literacy to empower information user communities. Digital divide s even witnessed among professionals who are working in the digital environment. Beside the rapid spread of the internet the gap is growing wider as the technological standards grew even faster networks, high level machines and many soft ware and more capable professionals are also required. It is therefore important to identify that a literacy programme is designed for whom and what impact it has on learners. Any information literacy programme should be interesting keep the learner thinking and engaging make them realize what they have been missing so far and should have rippling effect on the world of participants. In India some efforts have been made here to bridge the digital divide The wireless in local loop technology development by IIT Chennai has providing the internet connectivity to 250 community that offer these services to 700,000 people in rural India.(Gaur, 2003). The key to effectively building collection in the digital era is also training of library professional because if they learn how to make most effective use of technology, the latter will automatically get involved in their work culture. They will thus also help to bridge the digital divide by training the information users. (I.V.Malhan, 2009).

\section{Digital Divide in Library and Internet}

As popular as library computer are with patrons and libraries an original goal of the investment in libraries was to help "bridge" to computers is not enough to bridge the digital divide, the skills and knowledge to use information technology effectively are equally important. One must have the interest to learn so library environment meet these requirements through their legacy as institutions of public education and most important through the librarians themselves. Informal one-one assistance from libraries has the additional benefit of teaching basic computer skills in the context of the patron own search for information. Research in information literacy and user behavior has shown that technical skills are best learned when they are thought in a problem solving context. An uncertain library patron wishing to engage online resources presents an ideal training opportunity this is exactly where librarians are making their impact on the digital divide.(www.pewinternet.org), (www.ntia.doc.gov, 22 dec, 2003).

\section{Role of Libraries and Information centers in bridging Digital Divide}

Libraries have their computers wired for the internet and available for public use, also the valuable human resource they provide libraries to help visitors find their way bring technology in to our communities in friendly and useful ways for workers who will not access to the internet in their homes or on their jobs. Having internet access, people can reach to public officials to non-profot organizations to the public which they serve having provide quality of the public services provide to the community. Libraries have now many working families need to carry out all this vision of access leading to community action and improvement.

Access

working Libraries can now open the way to the way to the web by providing people with the some access to Internet resources that others have, so libraries are connect for the Internet so people have use their neighborhood library to go online, and gain access to their local union website or any other website that needs their needs.

\section{Training}

Librarians and other library professional can help working people get more comfortable and skilled with using computers and surfing the World Wide Web.

\section{Education}

Libraries are now provide adult education programme, as literacy classes and also GEN exams are an important resources that working people can use to get better jobs for themselves and their families. All these resources offer wonderful opportunities for union and libraries to form partnership for bridging the digital and 
information divide. Librarians can also help working people to get online to use the web through access for those without computers, training and encouragement to help them get over fears of using new technology.

The workers could also go to the library community technology centre to set up a free web-email account and use the local web site to get information on action needed from their co-workers and community organization working together, libraries and working people can fulfill the promise of using new technology for effective communications.

\section{Academic Libraries}

The national knowledge commission (2007) has made a recommendation that all academic institutions must set up an international repository of ETD. So the libraries should go for an effective resource sharing network although there are certain efforts taken at the regional level such as (ALIBNET, MALIBNET, ADINET, and PUNET) etc. Libraries should continuously orient their users with modern information in having access to information, communication and technologies which can ultimately results in bridging digital divide. Bridging the digital divide - the best academic library in India has a budget 25\% of the lowest ranked of 100 surveys in 2001 of ALA membership. (Dasgupta,S.K).

\section{Digital Divide in Libraries and Library professionals}

In this information age, it is recognize that information is the core of all developmental activities where libraries have the key role in all collecting, storing, and disseminating the universal information. But libraries are not getting adequate attention and care while chalking out action plans for digital divide. Many education institutions are now conducting in-house training programme for their library professionals. Efforts of educational network and special network have an appreciable role in this matter many rural libraries are now here in the scene. They are facing with technological manpower and financial crunch. Some of their basic constraints are

1. Crisis in getting sufficient fund

2. Crisis in development of manpower

3. Crisis in conducting staff training programme-to improve working quality

4. Crisis in getting qualitative housekeeping soft ware

None availability of resources in digital form leading to lack of proper information services. So government and local bodies should give proper attention to these areas. An action plan should be framed for development of rural libraries. Earlier public libraries were providing government information leaflets and other documents. But when the emphasis shifted from print to digital information libraries espically public libraries are facing many barriers to change their environment appropriately by digital information storage retrieval and dissemination. This has created a digital divide among libraries and library professionals working in different organizational setup as the public libraries are having the closest links with rural community.

\section{Rural Libraries and Community information Centre}

Rural libraries are the grass root nets of public library system and nearest link with the rural community. But government and other agencies working for digital divide do not give proper important to rural libraries even though one rural library from every panchayat is selected for implementing information Kerala mission to act as community centre. It will not be effective if rural librarians are not trained in the management of digital information access and preservation, especially in exploring the possibilities of internet and give IT enabled services for rural community by giving proper training in digital rural library care takers they can be converted as good managers of CIC and help in the building contexts. The library in a particular locality may become a clearly house for contentinformation on community organizations, services, etc. It may provide specialized services both inside and outside the library building such as job information for a community with high unemployment. The library may create local directories maintain files of service agencies. (Abraham.L.T, 2008)

\section{Conclusion:}

Impact of having public access especially for those do not have alternative access to computer, internet and online information is very significant. The primary recommendation for empowerment of service in public libraries. Public libraries are more significant in bridging the gap of digital divide.

\section{References:}

[1]. Abraham, L.T, (2008). Tackling Digital Divide in Kerala and the possible role of libraries, Library Herald, Vol.46-No-2, p.128.

[2]. Bajwa, G.S. (2003). ICT policy in India in the era of liberalization: Its impact and consequences. Global Built Environment Review 3, 49-61.

[3]. Bansode, S.Y (2008). Bridging Digital Divide in India: Some initiative, p.60.

[4]. Behera, J.K (2011). Problems and challenges of collection development of Indian Libraries in Digital Era An Assessment, Researchers World -Journal of Arts Science and Commerce, ISSN-2229-4686, p.139.

[5]. Biswas, S. (2001). Digital empowerment seeds of Evolution, Retrieved 9 April, from www.outlookIndia.com. 
[6]. Dasgupta, S.K (2002). The idea of a digital library: Issues of Today, Vol.2555, 2002, p.518.

[7]. Dorr, J. and Akeroyd, R. (2002). New maxico tribal libraries: bridging the digital divide computers in libraries 21(8), http://www.infotoday.com).

[8]. Dragulanescu, N.G. (2002). Social impact of the "Digital Divide" in a central-eastern,34(2):139-151.

[9]. Dubey, P. (2010). A studies to examine the Digital Divide factors: Jammu and Kashmir perspective, BVICAM's International journal of information technology, 2010, New Delhi.

[10]. Gore, R.K. (2003). "Rethinking the Indian Digital Divide;; Present state of Digitization in Indian Management Libraries:" IN Murthy T.A.V.ed mapping Technology on Libraries and people, Ahmadabad, INFLIBNET, 2003, p.108.

[11]. Heeks, R. (1998). Information Age Reforms of the Public Sector: The Potential and Problems of IT for India, IDPM, University of Manchester, UK.

[12]. Keinston, K. (2004). The four Digital divide Retrieved 10 Jan 2011, from http://www.nla.gov.au.

[13]. Lesame, N. (ed.) (2005). New media Technology and policy in developed countries, 2005,p.255.

[14]. Lor, P.J.(2002). National libraries and the digital divide Introduction to the panel discussion, p.3. www.lianza.org.nz).

[15]. Lucky, A.T. (2013). The effect of Digital Divide on information Accessibility among undergraduate students of AhmaduBello University Zaria, Research Journal of Information Technology 5(1):01-10, ISSN: 2041-3106, pub-March- 01-2013.

[16]. Malhan, I. V. (2009). Trends of building and accessing digital collections and problems of digital divide in the emerging digital era, Srilankan Journal of Librarianship and information management, Vol. 2, No-1, p.5-10.

[17]. Mallikarjun, B. (2004). Indian Multilingualism language policy and the digital divide, 2004,Retrieved 15 Jan 2011, from http://www.languageindia.com/april.

[18]. Naughton, J. (2003). Eastern space: The internet and global civil society, chapter6, 2001,(http://www.ise.ac.uk, accessed 1 may 2003.

[19]. Neena, S. (2007). Bridging the digital Divide in India: Some challenges and opportunities, world libraries, Retrieved 15 dec 2010 , from http://www. Worlib.org/vol.no,1/pring/singh-print-html.

[20]. Osunkule, O. (2008). "Bridging the digital divide and the impact of new media technologies on development in south Africa", p.377(www.intechopen.com).

[21]. Paul (2002). Narrowing the digital Divide: Initiatives undertaken by the Association of south-east Asian Nations (ASEAN) prog electronic library and information systems 36(1):13-22., (http://www.emraldin sight.com).

[22]. Singh, K. (2012). Digital Divide factors in Indian management libraries, International journal of Advanced Research in IT and Engineering , ISSN:2278-6244, vol.1, No-3, sept, IJARIE-35.,2012,(www.graph.co.uk)

[23]. Stevenson, R.L. (1988). Communication development and the Third World: The global politics of information. New York: Longman, p.35.

[24]. Tharayil, A. J. (2003). To-wards bridging the digital divide in India: Challenges and opportunities from a national perspective, 2003, p.6.

[25]. Warschauer, M. (2010). Digital Divide, p.1551-15556, Enclopedia of Library and information science-3rded., DOI:10-1081/ELIS3-120043692c@2010by Taylor and Francis.

[26]. Wolf, L. (2002). What is digital divide? July-sept, p.8, (www.techknowlogia.org).

[27]. Wynne, M.E. (2007). Digital Inclusion imperatatives offer municipalities (A white paper), p.4-5. (www.microsoft.com).

[28]. Yoffie, D. B. (1996). Competing in the Age of Digital Convergence, California Management Review, Vol. 38, No. 4 